\title{
BLOCKCHAIN FOR GLOBAL MARITIME LOGISTICS
}

\author{
Ashraf Shirani, San Jose State University, ashraf.shirani@sjsu.edu
}

\begin{abstract}
Global maritime logistics generates annual revenues upwards of two trillion dollars, more than one-fifth of which is earned by freight forwarders and other intermediaries facilitating the trade. Multiple entities in the supply chain, with their disjointed and often incompatible administrative procedures, outdated paperwork practices, and competing interests, add a great deal to the cost and time for exporters and importers. This study examines the feasibility of a blockchain-based approach to enhancing transparency, efficiency, and economy of the global maritime logistics and finds the approach much promising. A proof-of-concept Web client application, built using Linux Foundation's Hyperledger Sawtooth framework, is used to describe the functionality of a potential maritime logistics blockchain.
\end{abstract}

Keywords: Blockchain, Distributed Ledger, Containerized Shipping, Maritime Logistics

\section{INTRODUCTION}

Blockchain, with a relatively short history has garnered large interest, though most noticeably from general public and specifically for its use in enabling bitcoin and other crypto-currencies. Although not as visible or hyped as the digital currencies, many private enterprises, consortiums, and government agencies have been busy conducting research and development to harness the technology and using its fundamental tenets for reengineering their business processes and introducing new business models. The objective of this paper is to examine the feasibility of using a blockchain for maritime containerized logistics. As part of this objective, a Web based proof-of-concept prototype application was developed to demonstrate potential functionality of such a blockchain. The paper also includes detailed description and a walk-through of the prototype.

According to IBM (2018), "blockchain is a shared immutable ledger for recording the history of transactions". This concept behind the blockchain technology has a tremendous potential for creating cost-effective and efficient business networks for trading anything of value between and among interested traders without requiring an intermediary party or central authority. Although it is commonly described as a new and innovative technology, blockchain is actually not a single technology. Implementing a blockchain entails a new way of cobbling together a number of existing tried and tested technologies, methods, frameworks, and protocols into a permissioned or permissionless network for information sharing and transaction processing. Some of the important techniques and technologies that have come together in this ensemble include public and private communication networks (such as peer-to-peer networks), distributed databases, state machines and logs replication, cryptography, consensus algorithms, concurrency control, and more (Olson et al., 2018). Cryptographic signatures are used to ensure security and correctness of transactions. Together with distributed consensus among trading parties and the non-repudiation property of blockchain transactions once the consensus is reached, blockchain ensures consistency.

As an example of the growing interest by the US and other governments, in 2016 the US Department of Health and Human Services sought research proposals to examine potential use of the blockchain technology in "patient centered outcomes research (PCOR), precision medicine, and other health care delivery needs, as well as provide recommendations for blockchain's implementation." (USDHHS, 2016). Other governmental agencies including the US Department of Homeland Security and the Department of Defense recently awarded research contracts to explore possible use of the blockchain technology. The Defense Advanced Research Projects Agency (DARPA) sought to develop a secure messaging system using a distributed ledger for encrypted communications, and NATO announced a technology innovation contest in 2016 to explore the use of blockchain in battlefield applications and other related tasks (Coindesk, 2016). Sweden's land mapping and registration authority is planning to test its blockchain based real estate system to conduct property sale in 2018. It is currently seeking volunteers to buy or sell property using this system (Anand, 2018). 
Even more enthusiastically than governmental agencies, major corporations in the US and around the world are investing in research and development of blockchain-based systems to augment existing ones, and offer new products and services. Corporate spending on blockchain technology is estimated to exceed 2 billion dollars in 2018 from under one billion in 2017 (Nash, 2018). Walmart recently tested a blockchain based produce tracking application using which an employee can scan a single piece of fruit such as a mango in a Walmart store in the US and know the farm where it came from. More than one million items on sale or sold in Walmart stores are said to be currently on the blockchain (Mims, 2018). Last year, British Airways tested a blockchain based flight information system to ensure data consistency to prevent displaying inconsistent information at different locations such as airline gates, airport monitors, and the company's websites (Nash, 2018). A major global shipping company, Maersk, is said to be using the blockchain technology developed by IBM to track sea-borne containers and expedite customs clearance (Mims, 2018). One of the "Big Four" accounting firms, PricewaterhouseCoopers (PwC), plans to offer an auditing application to validate block-chain based transactional systems. It is currently testing an application that is meant to audit and verify its clients' blockchain based systems to ensure that they are compliant of the legal and regulatory requirements (Rapoport, 2018). The PwC application has reportedly been tested by a number of its clients including one major stock exchange that needs to verify its blockchain-based payment process.

In summary, one of the core features of the blockchain technology is disintermediation: blockchain technology promises to confer the aforementioned capabilities and benefits without requiring any central authority or intermediaries. Another property of interest of the blockchain based business models is their maintenance of distributed and immutable sets of records of asset ownership, transfer, and transactions. Inherent in disintermediation and distributed record keeping, however, are potential challenges as well. For example, lack of a central authority to administer and audit transactions in a number of cryptocurrency offerings may have facilitated fraud and rendered them vulnerable to abuse and crime (Ramey, 2018). Also, although it is extremely difficult to make unauthorized modifications to the distributed blockchain data, it is certainly not impossible to do so. It is therefore prudent to better understand and carefully weigh potential benefits and challenges for each blockchain use case before implementing this technology.

The next section contains detailed description of a specific supply chain use case with focus on maritime containerized logistics. The section that follows the next section describes a simplified scenario of this use case with the help of the proof-of-concept application prototype. The last section concludes the paper with a summary, limitations of the study, and possible directions for further research.

\section{GLOBAL CONTAINERIZED LOGISTICS AND THE CASE FOR BLOCKCHAIN}

Global container shipping is an essential part of the global trade. An estimated $\$ 4$ trillion worth of manufactured goods, heavy machinery, raw materials, food, and consumer goods are moved around the world in shipping containers (Costas and Tsuneoka, 2018).

Containerized shipping supply chain is highly fragmented. Besides sea-borne transportation, the shipping supply chain has numerous players at each step of the shipping process: domestic transportation - typically by road, rail, and some air modes; multiple freight forwarders; warehouse and docks owners and operators; port authorities, often with differing policies and political jurisdictions. Figures 1(a) and 1(b) below show participants in a typical containerized shipping supply chain. 


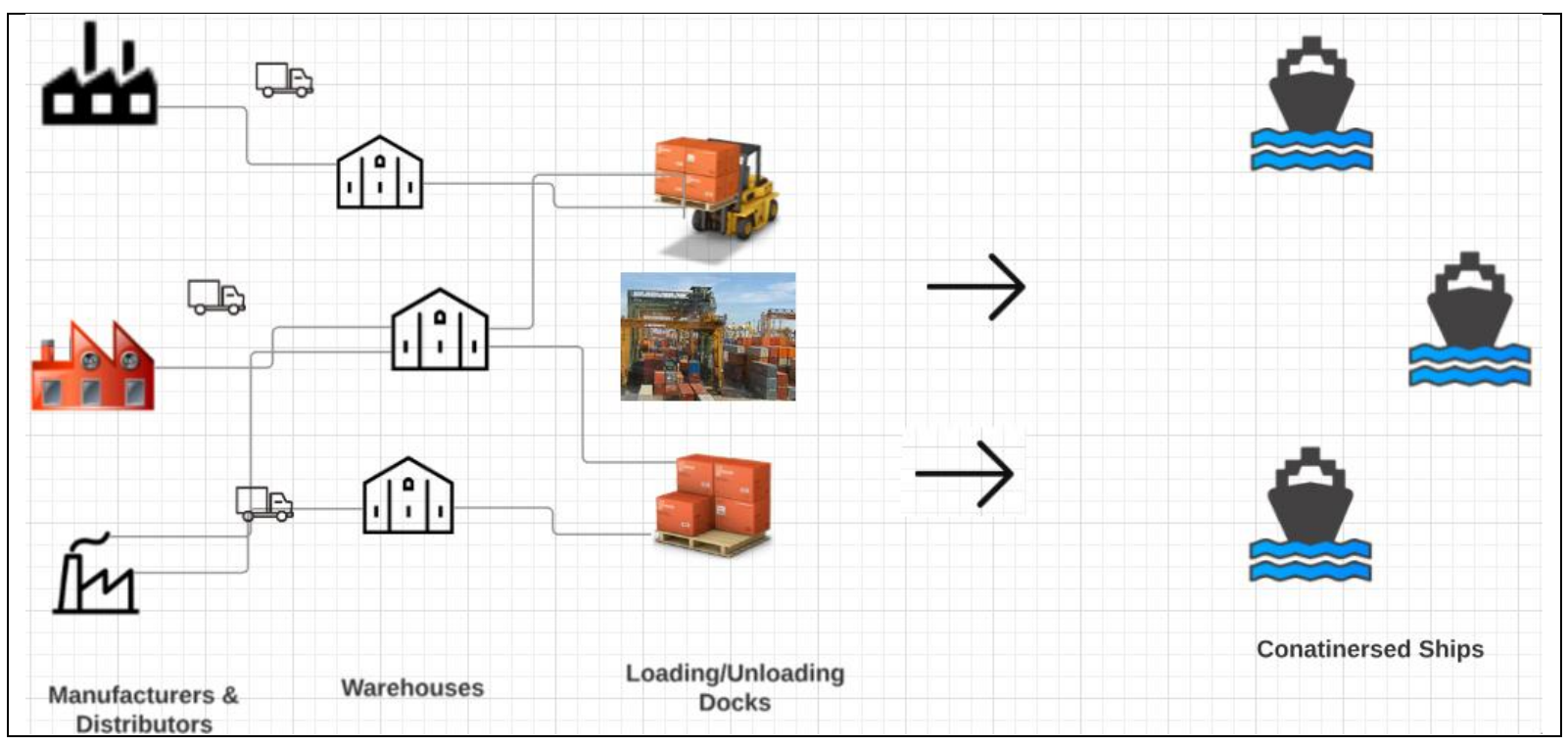

Figure 1(a). Outbound Segment of Containerized Logistics

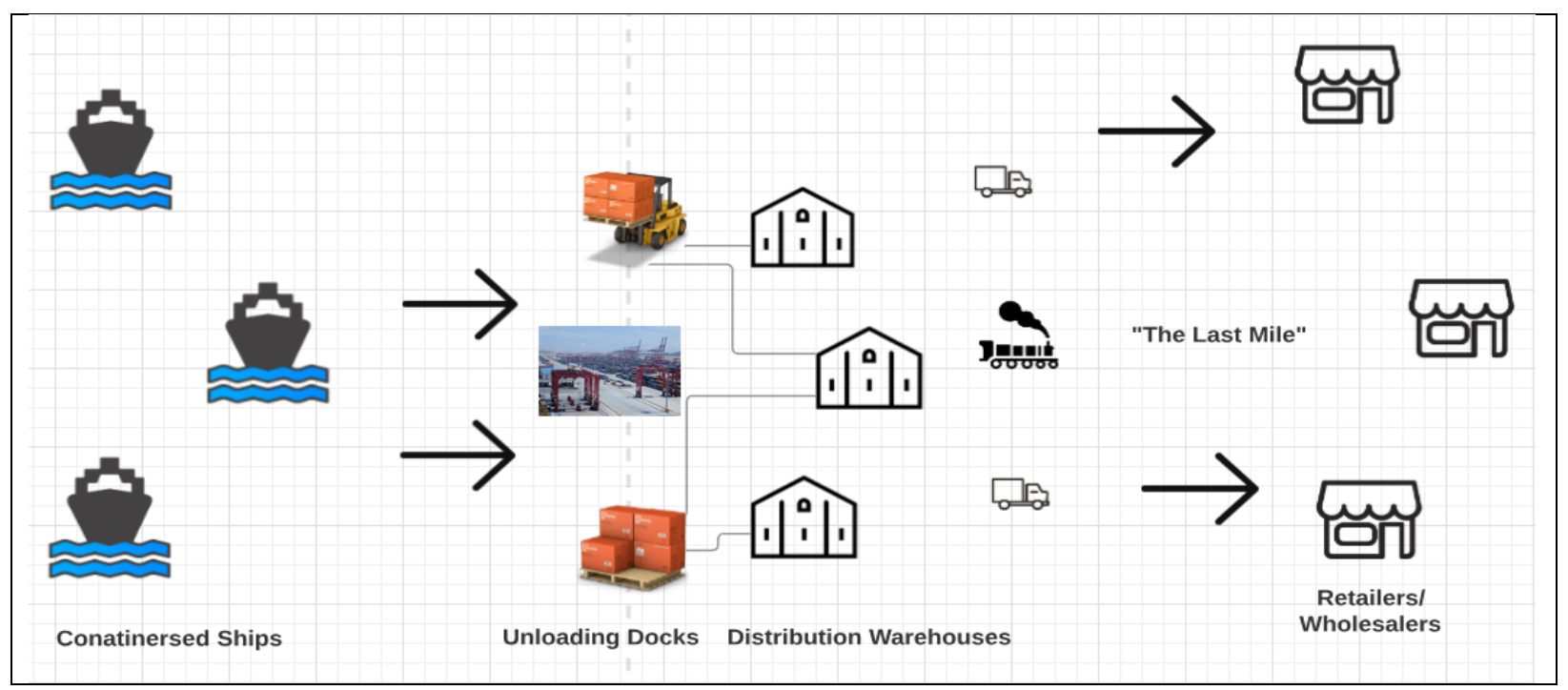

Figure 1(b). Inbound Segment of Containerized Logistics

Information systems and operating procedures of various participants in the global shipping supply chain are often different and incompatible; many of them have business processes that are paper-based, even today (Economist, 2018). This adds to the total cost and delays for importers, exporters, and the shipping companies. Due to high costs and low profit margins, a number of smaller containerized shipping companies have either abandoned their business, consolidated, or were bought by larger ones during the last decade. A conspicuous display of this trend was the 2016 failure of the world's eighth largest shipping company, South Korea's Hanjin Shipping (Economist, 2018).

\section{Motivations for Adopting the Blockchain}

There are compelling reasons for policy makers, governments, and shipping companies around the world to modernize, digitize, and integrate their systems and infrastructure to facilitate global trade, including maritime trade. And the blockchain technology has the potential to be an essential part of such modernization as discussed below.

Global Shipping - a Strategic Asset: For many countries, especially major world economies, global commercial shipping is increasingly viewed as an important strategic asset (Costas and Tsuneoka, 2018). China's recent $\$ 900$ 


\section{Issues in Information Systems}

Volume 19, Issue 3, pp. 175-183, 2018

billion "Belt and Road" initiative is a vivid demonstration of this view. Increasing adoption and use of blockchain technology by their trading partners worldwide would make it necessary for many governments and importers and exporters to participate in these initiatives or risk losing their trade and competitiveness.

Time and Cost Savings: A large proportion of the around $\$ 3$ trillion non-domestic cargo shipping is earned by freight forwarding companies that deal with customs clearance, transfers between sea and land, and procedural and logistics matters. Besides bureaucratic delays, outdated procedures and a mix of digital and paper-based forms add to the inefficiencies in global supply chains. To address this problem, a number of shipping companies such as Amazon.com and Deutsche Post/DHL are beginning to vertically integrate parts of their supply chains with their operations by having in-house freight forwarding (Economist, 2018) and thereby effectively removing intermediaries for time and cost savings. Core features of the blockchain such as its support for disintermediation and making consistent, real-time information available online, can help save a great deal in time and money.

Need for Transparency: Since many freight forwarders typically charge by a percentage of the total cost, they have the incentive to increase rather than reduce total costs. A blockchain can help eliminate unnecessary steps in the process and shed light on the entities and steps that may be responsible for unnecessary costs and delays. For example, a number of major companies including AT\&T, Kellogg, Bayer, and Nestle are participating in blockchain initiatives to gain visibility into their online advertising campaigns to know exactly how many real people (and not robots) are actually viewing their ads and how much of their ads budgets are spent on ad agencies and other intermediaries vs. the online publishers (O'Reilly, 2018). Doing so would help these companies better negotiate with the intermediaries and reduce their costs.

\section{Blockchain's Synergistic Relationship with Other Technologies}

As noted earlier in this paper, blockchain is not a single technology but rather it benefits from a number of other enterprise technologies and practices including distributed database, encryption, peer-to-peer networks, and more. With its lineage as a technology ensemble and its enterprise-grade features supporting decentralized collaboration, it will no doubt continue to benefit from many current and emerging technologies. Figure 2 shows a few of the ways currently popular technologies can help augment blockchain's functionality.

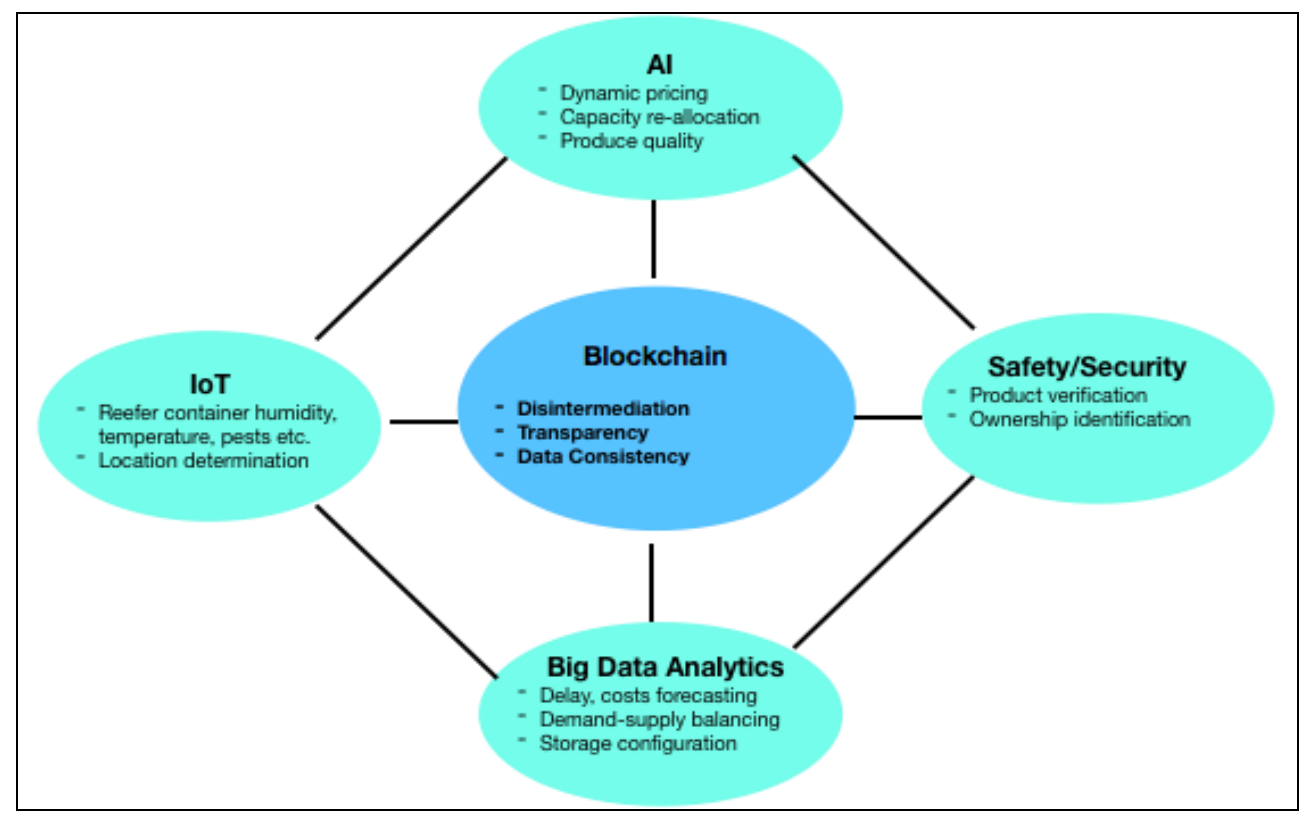

Figure 2. Blockchain's Synergy with Other Technologies 


\section{A PROOF-OF-CONCEPT APPLICATION PROTOTYPE}

The purpose of the proof-of-concept prototype is to describe the functionality of a potential blockchain for maritime logistics. This application was created using the Linux Foundation's open source Hyperledger Sawtooth framework, which is a collaborative project to advance cross-industry blockchain technologies. Among the industry leaders participating in this collaboration are those from banking, finance, supply chain, manufacturing, and information technology (Olson et al., 2018). This prototype is adapted from an open source application developed by Zac Delventhal (2018), a maintainer at Hyperledger Sawtooth, and a related online course offered jointly by edX.org and the Linux Foundation (2018).

\section{Structure of the Blockchain Application}

Hyperledger Sawtooth is a modular platform for building blockchain applications, which allows building business applications independently of the core system. The platform's modular structure enables adopting any of the available consensus algorithms and smart contract protocols relevant to the use case or application. Also, the Hyperledger platform is highly scalable and thus most suitable for implementing supply chain solutions. Business applications typically include server-side business logic, and Web, command line, and mobile clients. The system maintains a record of asset ownership as well as provenance of transactions. It groups related transactions into batches, and batches in to blocks. Each batch of transactions is treated as an atomic unit, i.e., all transactions in the batch must successfully complete for the batch to be stored in the distributed database. A typical structure of the blockchain applications is shown in Figure 3.

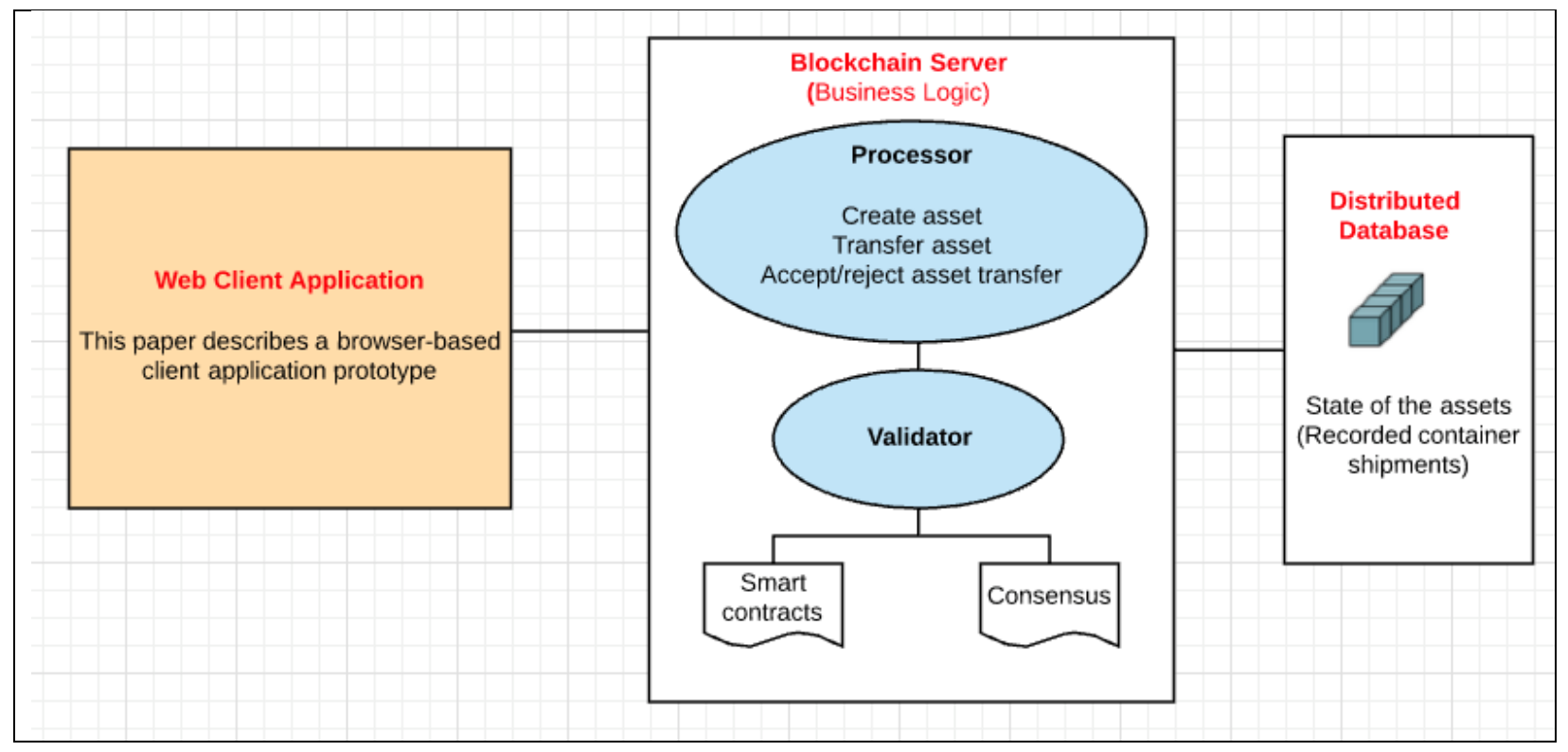

Figure 3. Blockchain's Application Structure

A software module called transaction processor provides business logic in the applications. Each node in the blockchain network may run one or more transaction processors -one transaction processor for each application or use. All nodes in the network must run the same sets of transaction processors. Also, all nodes must maintain a shared global state of the blockchain including asset ownership and lineage of transactions.

\section{Maritime Blockchain Participants}

One essential requirement for adopting a business blockchain is that all participants in the blockchain network must agree to sign up on a common set of rules (O'Reilly, 2018). In a global supply chain that inherently embodies multiple political jurisdictions, disparate technologies and business practices, and competing interests, this may 
prove to be a major challenge. Contentious issues may include agreement on a common consensus algorithm, and privileges each type of participant or role may have in terms of CRUD (i.e., create, read, update, and delete records). These and other potential obstacles to implementing blockchain technology for global maritime logistics require further research.

For the simplified global maritime logistics use case described here, categories of participants along with their permissions to create, transfer, and accept/reject transfer of assets are listed below.

Exporters: Participating manufacturers, wholesalers, or their agents would have the permissions to read (view) and create records of their assets (typically containers) for export.

Importers: Organization, individuals, or their agents would have the permissions to read as well as accept and reject transfer of assets from exporters.

Port authorities: Authorized personnel at exporting, importing, and intermediary ports would have read privileges necessary for them to perform their job responsibilities such as inspect assets (containers), allow or disallow transfer of assets, and assess duties and charges.

Shipping companies: Shipping companies and their authorized agents would have privileges to read/view records of assets and inspect assets.

\section{A Client Application Walk-Through}

Hyperledger software development kit (SDK) is available in a number of programming languages including JavaScript, C++, GO, and Python. JavaScript SDK was used for creating this Web client application prototype, which is a simple user interface as shown in Figure 4.

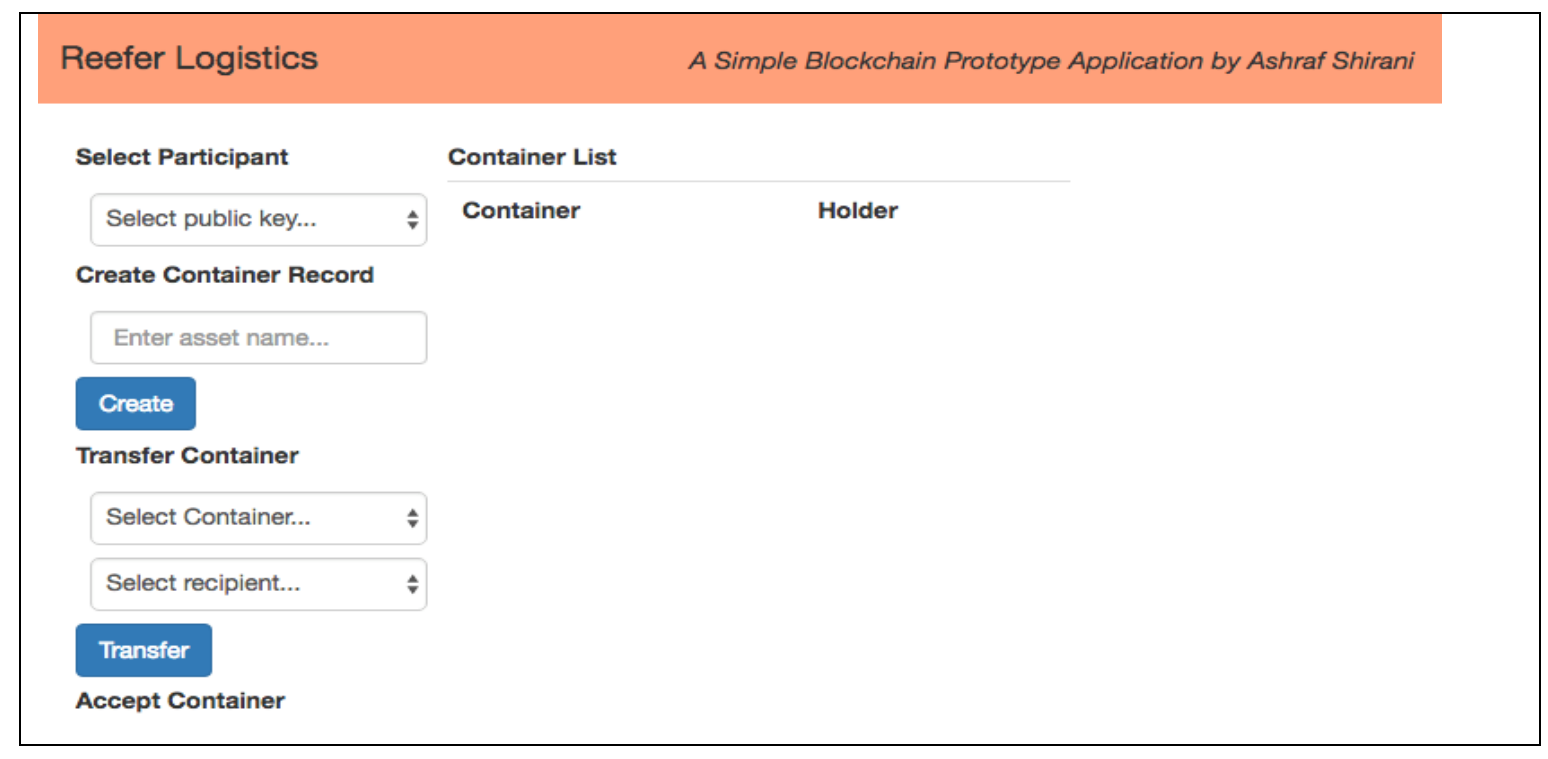

Figure 4. User Interface of the Application

Typical tasks that can be performed using this Web based client application include adding participants, creating new assets, transferring assets from one owner to another, and accepting or rejecting an asset transfer. This functionality is demonstrated by a walk-through of the application as described below.

Add participants: A new participant can be added by creating a new private/public key pair, as shown in the Figure below: 


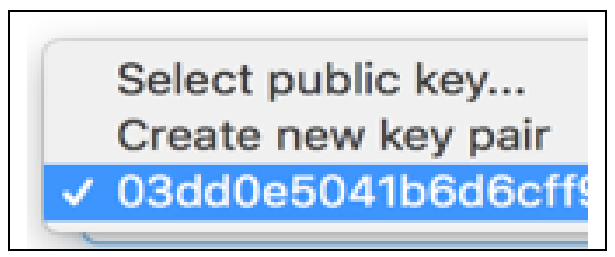

Figure 5. Adding a Participants

Create a new asset: Creating a new asset, which is a shipping container in this use case, requires specifying a unique name for the asset and then clicking on the "Create" button:

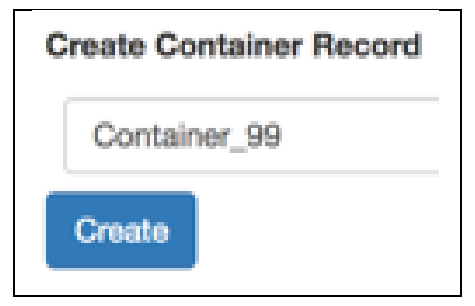

Figure 6. Creating a New Asset

Transfer an asset: Assets can be transferred from one participant of the blockchain to another. Participants are referenced by private/public key pairs. When transferring an asset from one holder (owner) to another, one needs to select an existing public key for the current holder of the asset, name of an existing asset to be transferred, and public key for the participant to whom the asset would be transferred. For example, in the left pane of the following screen-capture in Figure 7 we see a shipping container, Container_99, being transferred from a holder whose public key begins with characters $03 \mathrm{f}$ to a participant whose public key begins with characters $03 \mathrm{~d}$. The right-side pane of the screen-capture shows new ownership of the container after the transferred is completed.

\begin{tabular}{|c|c|c|}
\hline Select Participant & \multicolumn{2}{|l|}{ Container List } \\
\hline 03f12205709a4368915d63a7668cfd8dfb1021299303699eeca2de8296b43bc8c2 & Container & Holder \\
\hline Create Container Record & Container_99 & 03dd0e5041b6d6cff9c2e9d0eb2eb7de3743de682550461741d5c892a9d0f63b35 \\
\hline Container_99 & & \\
\hline \multicolumn{3}{|l|}{ Create } \\
\hline \multicolumn{3}{|l|}{ Transfer Container } \\
\hline Container_99 & & \\
\hline $\begin{array}{l}\text { Select recipient... } \\
\text { 03dd0e5041b6d6cff9c2e9d0eb2eb7de3743de682550461741d5c892a9d0f63b35 } \\
\text { 03f12205709a4368915d63a7668cfd8dfb1021299303699eeca2de8296b43bc8c2 }\end{array}$ & & \\
\hline Accept Container & & \\
\hline
\end{tabular}

Figure 7. Transferring an Asset

Viewing assets ownership: After each transfer, the client interface displays the current list of assets and their owners, represented by their public keys as in the following Figure. 
Issues in Information Systems

Volume 19, Issue 3, pp. 175-183, 2018

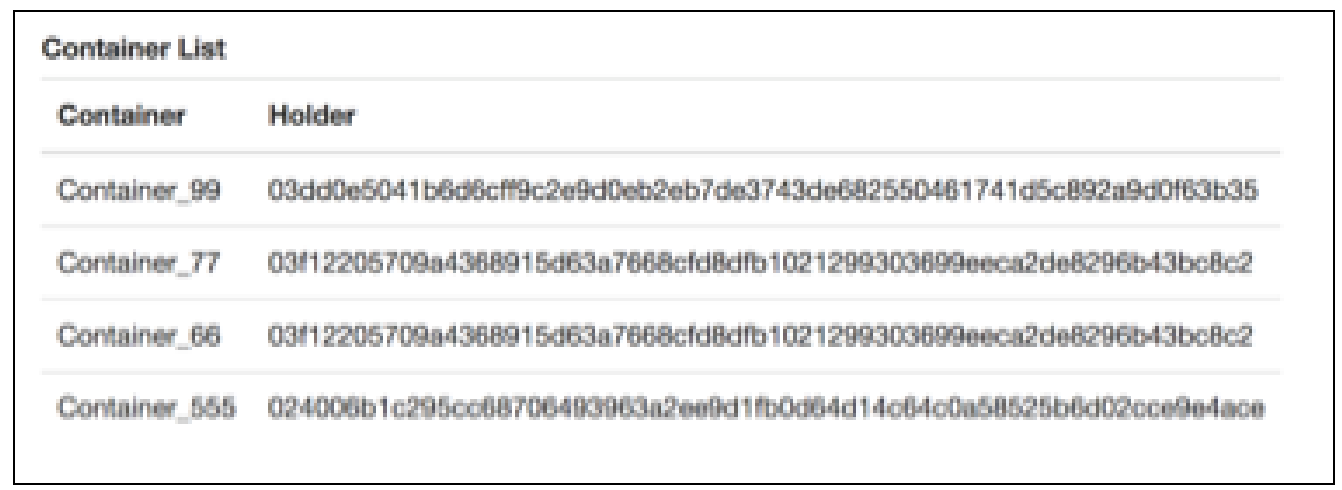

Figure 8. Viewing Asset Ownership

\section{CONCLUSION}

In this paper, the author examined potential adoption and use of the blockchain technology for global sea-borne containerized logistics. Review of relevant literature indicates that trading partners and shipping companies would benefit greatly by adopting this technology. Gains are expected to be realized through reduced use of intermediaries, especially the freight forwarders who, by some estimates, account for over $20 \%$ of the total cost of logistics. Additional benefits of using a blockchain would save in total shipping time and thereby boosting global trade and employment. As an example, the United Nations' estimates suggest that by putting the Asia Pacific's trade related paperwork online would save as much as $44 \%$ in time (The Economist, 2018). Furthermore, real- or near-real time availability of data in the blockchain about location, condition, and movement of goods would enhance visibility for importers and exporters into their supply chains and help them make better-informed decisions in sales, marketing, logistics, and other areas. A proof-of-concept prototype application is also discussed in the paper. It includes a walkthrough of the prototype application to demonstrate essential functionality of a potential blockchain for global maritime trade.

The field of global trade and logistics has a broad scope that requires multi-lateral coordination and negotiation among several organizations, governments, and regulatory agencies for successful execution. One limitation of this study is that it offers a high-level view of this field's technological and business landscape. In-depth research into its component areas is necessary to bring the concepts offered in this study to fruitation in the form of a fully functional blockchain.

Earlier in this paper four technological fields were identified as excellent candidates for synergistic relationship with the blockchain technology. As depicted in Figure 2, these areas include artificial intelligence (AI), the Internet of Things (IoT), cyber security, and big data analytics. Further research may examine how these technologies may be incorporated in the blockchain and the resulting data and insights into decision support. As an example of integrating IoT into a blockchain network, Hyperledger Sawtooth module called Supply Chain may be used. This module helps track refrigerated containers (known as "reefers") through the supply chain and collect telemetry data such as temperature and humidity. The main reefer trade routes are from Southern hemisphere (South America, South Africa, Australia, New Zealand) to Northern hemisphere countries and this trade is growing at the rate of 56\% annually (Paris, 2018). Refrigerated containers can keep food fresh for about a month and are often used to ship fruit, seafood, and other perishable goods. Such telemetry data could be of great value in transportation, warehousing, pricing, and product sourcing decisions.

\section{REFERENCES}

Anand, S. (2018, March 7). Test of blockchain for real estate is readied. The Wall Street Journal, pp. B8.

Coindesk. (2016). US government awards $\$ 600 \mathrm{k}$ in grants for blockchain projects. Retrieved from https://www.coindesk.com/us-government-grants-blockchain-projects/ 
Delventhal, Z. (2018). Hyperledger sawtooth blockchain application Retrieved from https://github.com/delventhalz/transfer-chain-js

edX.org, \& Linux Foundation. (2018). Blockchain for business - an introduction to Hyperledger technologies. Retrieved from https://www.edx.org/course/blockchain-business-introduction-linuxfoundationx-lfs 171x-0

Egloff, C., Sanders, U., Riedl, J., Mohottala, S. \& Georgaki, K. (2018). The digital imperative in container shipping. Retrieved from https://www.bcg.com/publications/2018/digital-imperative-container-shipping.aspx

IBM. (2018). What is blockchain? Retrieved from http://www.ibm.com/blockchain/what_is_blockchain.html

Mims, C. (2018, March 12). Blockchain has power to transform. The Wall Street Journal, pp. B4.

Nash, K. (2018, February 7). Walmart, British Air try out blockchain technology. The Wall Street Journal, pp. B5.

Olson, K., Bowman, M., Mitchell, J., Amundson, S., Middleton, D. \& Montgomery, C. (2018). Sicep: Sawtooth: An introduction. Retrieved from https://www.hyperledger.org

O'Reilly, L. (2018, July 13). Blockchain helps track web ads. The Wall Street Journal, pp. B4.

Paris, C. (2018, April 30). Shippers reap new profits by transporting fresh food. The Wall Street Journal, pp. B3.

Paris, C., \& Tsuneoka, C. (2018, May 12-13). Japanese shipping merger follows trend. The Wall Street Journal, pp. B2.

Ramey, C. (2018, May). The crypto crime wave. The Future of Everything: A Look Ahead from the Wall Street Journal, 58-62.

Rapoport, M. (2018, March 17-18). PwC has an answer for blockchain: Audit it. The Wall Street Journal, pp. B10.

Sanders, U., Faeste, L., Riedl, K.,Jens, Egloff, C., Lee, D. \& Italiano, J. (2015). The transformation imperative in container shipping. Retrieved from https://www.bcg.com/en-us/publications/2018/digital-imperativecontainer-shipping.aspx

The Economist. (2015, October 31). Blockchains: The great chain of being sure about things. The Economist, Retrieved from https://www.economist.com/news/briefing/21677228-technology-behind-bitcoin-letspeople-who-do-not-know-or-trust-each-other-build-dependable

The Economist. (2018, April 28). Thinking outside the box: Digitisation will not just transform how goods are moved around the world, but also how the world shops. The Economist, 20-22.

US Department of Health and Human Services. (2016). US government issues call for blockchain healthcare research. Retrieved from https://www.coindesk.com/health-human-service-department-seeks-blockchainpapers/

Vigna, P., \& Oberman, J. (2018, January 24). The man behind a bitcoin uproar. The Wall Street Journal, pp. B1. 